\title{
Desempenho ponderal, aspectos econômicos, nutricionais e clínicos de caprinos submetidos a dois esquemas de suplementação mineral ${ }^{1}$
}

\author{
Pedro Malafaia², Viviane Antunes Pimentel ${ }^{3}$, Karen Purper Freitas ${ }^{3}$, Cleide Duarte \\ Coelho ${ }^{4}$, Marilene de Farias Brito ${ }^{5}$ e Paulo Vargas Peixoto ${ }^{2}$
}

\begin{abstract}
Malafaia P., Pimentel V.A., Freitas K.P., Coelho C.D., Brito M.F. \& Peixoto P.V. 2003. [Daily weight gain, economic, nutritional and clinical aspects of goats receiving two types of mineral supplements.] Desempenho ponderal, aspectos econômicos, nutricionais e clínicos de caprinos submetidos a dois esquemas de suplementação mineral. Pesquisa Veterinária Brasileira 24(1):15-22. Depto de Nutrição Animal e Pastagem, Instituto de Zootecnia, UFRRJ, Km 47, Seropédica, RJ 23835-000, Brazil. E-mail: malafaia1@ ig.com.br

Daily weight gain, economic, nutritional and clinical aspects of goats receiving two types of mineral supplements were evaluated during 148 days in Seropédica county, Rio de Janeiro, Brazil. The animals were daily fed with fresh and chopped Andropogon gayanus or Pennisetum purpureum; the concentrate ration was formulated without a mineral mixture and was offered together with the forage of 300 up to $500 \mathrm{~g} /$ animal/day. Sixteen goats were divided into two groups of 8 animals each (4 small and 4 larger goats). For one group a commercial mineral mixture was used, and to the other group a selective mineral mixture containing only $\mathrm{Na}, \mathrm{P}$ and $\mathrm{Cu}$ was offered. The animals were weighed every 30 days and the mineral supplement intake was measured monthly. Blood samples were collected at the beginning and the end of the experimental period. There was no difference in daily weight gain when the selective or commercial mixture was given for both groups. The selective mineral supplementation was 2.3 (for the smaller animals) and 3.9 (for larger animals) times more economic than the conventional supplementation with a "complete" mineral mix. The two groups showed recovery of hair quality and had an increase of hair pigmentation around the eyes, which was attributed to the correction of copper deficiency. In the larger animals the intake of both supplements increased the red blood cells counts, and the haematocrit and haemoglobin values. The forage intake was sufficient to meet the Ca and Co needs of the animals, and for $\mathrm{P}$ the concentrate intake was sufficient to overcome the demand for this element. The requirement of zinc was supplied through the forage and the concentrate ration. Thus, when an adequate concentrate and a good quality forage is given, only the deficient mineral element(s) should be supplemented. In this specific case only $\mathrm{Na}$ and $\mathrm{Cu}$ should be given. The result of this experiment confirms the hypothesis that selective mineral supplementation - i.e. supplementation of the mineral element(s) deficient in the diet - was correct and can result in reduction of the cost with the mineral supplementation of a herd.
\end{abstract}

INDEX TERMS: Goats, copper deficiency, mineral supplementation, tropical forages.

${ }^{1}$ Recebido em 23 de setembro de 2003.

Aceito para publicação em 15 de outubro de 2003.

${ }^{2}$ Depto Nutrição Animal e Pastagem, Inst. Zootecnia, UFRRJ, Km 47, Seropédica, RJ 23835-000. E-mails: malafaia1@ ig.com.br, peixotop@ ufrri.br ${ }^{3}$ Estudante de Zootecnia, UFRRJ.

${ }^{4}$ Médica Veterinária autônoma, Laboratório LACANI, Rua Cândido Benício 1057, Praça Seca, Rio de Janeiro, RJ 21320-061.

${ }^{5}$ Depto Epidemiologia e Saúde Pública, Inst. Veterinária, UFRRJ, Km 47, Seropédica, RJ 23835-000.
RESUMO.- 0 desempenho ponderal, os custos e os aspectos nutricionais e clínicos foram avaliados em 16 caprinos (8 pequenos e 8 maiores) submetidos a dois tipos de suplementação mineral por 148 dias. Um grupo recebeu uma mistura mineral comercial e outro, uma mistura mineral (sal seletivo) formulado apenas com cloreto de sódio $(239 \mathrm{gNa} / \mathrm{kg})$, superfosfato simples (34 gP/kg) e sulfato de cobre (1244 mgCu/ $\mathrm{kg}$ ). Não houve diferença estatística no ganho de peso diário entre os grupos de animais que receberam o suplemento 
mineral comercial ou o sal seletivo. o menor consumo do sal seletivo (66\% do verificado na mistura mineral comercial), observado no lote de animais maiores, deveu-se ao teor mais alto de $\mathrm{NaCl}$ na composição desse suplemento; essa menor ingestão representou um gasto 3,9 menor na suple-mentação mineral desses animais. Em relação aos animais pequenos, houve um consumo exagerado do sal seletivo, durante os primeiros 3 meses e, depois dessa fase, o consumo de ambos os suplementos foi idêntico. Esse maior consumo pode estar associado ao fato de que os animais eram lactentes antes do experimento e, quando tiveram acesso ao sal seletivo contendo mais cloreto de sódio, possivelmente tiveram maior apetite para esse suplemento. Todos os animais que receberam os dois tipos de suplementação mineral apresentaram evidente melhora da qualidade da pelagem geral e aumento da pigmentação na pelagem periocular, o que foi atribuído à correção da moderada deficiência de cobre existente nos solos da região; pois o rebanho não recebia suplemento mineral antes do início do experimento. Nos animais maiores, ambos os suplementos foram capazes de aumentar o número de hemácias, a concentração de hemo-globina e o hematócrito. Pela análise mineral do capim e da ração, bem como da quantificação do consumo diário desses alimentos, demonstrou-se que apenas o consumo do volumoso foi capaz de fornecer o cálcio e o cobalto necessário aos animais maiores e, em relação à ingestão de fósforo, apenas o consumo da ração concentrada foi suficiente para suprir os requerimentos dos dois grupos de animais. As exigências de zinco foram supridas pela ingestão da ração e do volumoso. Além dos cálculos sobre o consumo de fósforo, cálcio, cobalto e zinco demonstrarem que as exigências desses minerais foram totalmente atendidas apenas com a ingestão da ração concentrada e do volumoso; clinicamente os animais não apresentaram quaisquer sinais diretos ou indiretos de deficiência desses elementos. Esses fatos reforçam a hipótese de que quando os animais são alimentados com rações concentradas e volumosos de boa qualidade, poucos serão os elementos minerais a serem supridos - especificamente, neste sistema de criação desta região, apenas o sódio e o cobre. Os resultados desse estudo endossam a idéia de que a suplementação seletiva, conceito que significa fornecer apenas os elementos minerais que efetivamente estão em falta na dieta dos animais, está correta, e implica em marcada redução nos custos com a suplementação mineral do rebanho.

TERMOS DE INDEXAÇÃO: Caprinos, desempenho ponderal, deficiências minerais, suplementação mineral.

\section{INTRODUÇÃO}

O fato incontestável de que vários minerais são necessários em numerosas reações metabólicas nos seres vivos, criou a equivocada percepção de que esses nutrientes sempre devem ser suplementados aos animais. Ou seja, acredita-se que, independentemente da quantidade de minerais presentes nos alimentos energéticos e protéicos, vários ou o maior número deles ainda deveriam ser disponibilizados, sob forma de suplementos, para que os animais tornem-se saudáveis e atinjam sua máxima produtividade. Tal prática, porém, além de não trazer qualquer benefício adicional, ainda representa um considerável acréscimo nos custos de produção e pode resultar na menor absorção, em função de antagonismos, daqueles minerais que realmente são necessários aos animais.

Em virtude de variações intrínsecas (nível de produção, raça, sexo, idade, estágio da lactação) e extrínsecas (parâmetros climáticos, consumo de alimentos, antagonismos, presença de fitatos), há uma dificuldade para se estabelecer o valor exato do requerimento mineral para os animais. Os atuais valores dos requerimentos descritos na literatura representam apenas uma média, muitas vezes pouco confiável devido à elevada variação dos dados gerados nesses estudos.

Outro ponto que não pode ser ignorado é o de que as estimativas dos valores médios dos requerimentos é feita com base nas exigências de animais de alto mérito genético, criados em condições praticamente ideais e com um padrão de alimentação bastante constante e homogêneo. Dessa forma, parece lógico pensar que os requerimentos minerais, preconizados como ideais pelo Agricultural and Food Research Council (AFRC 1993), pelo Institut National de la Recherche Agronomique (INRA 1989) e pelo National Research Council (NRC 1981) sejam diferentes para os animais com desempenhos produtivos mais modestos, criados nas condições do clima tropical, com as variações sazonais na produção e na qualidade das pastagens. Por outro lado, há que se levar em conta que, dependendo da concentração de minerais no solo da região, do tipo de manejo alimentar e do padrão genético, os alimentos, por si só, podem suprir todas as necessidades em minerais dos animais. De fato, em um estudo recente, sobre o desempenho reprodutivo de matrizes bovinas de corte, pôde-se demonstrar que apenas a suplementação com o cloreto de sódio foi eficaz quando os animais foram mantidos em pastagens bem manejadas e de bom valor nutritivo (Peixoto et al. 2003).

Até poucos anos atrás, os requerimentos minerais de várias espécies de ruminantes eram estimados, empiricamente, pela extrapolação dos requerimentos dos bovinos. Essa simples transferência de valores exigidos por uma espécie para a outra, pode resultar em distorções. Por exemplo, o leite de búfala contém aproximadamente $30 \%$ mais fósforo do que 0 da vaca (Zicarelli 2003). Recentemente, 0 avanço das pesquisas em nutrição mineral de caprinos proporcionou recomendações mais acuradas para essa espécie (Meschy 2000). Em comparação aos bovinos, verificou-se que os caprinos absorvem mais o fósforo da dieta $(70-75 \%$, suas exigências de cálcio e fósforo são maiores na fase final da gestação (partos gemelares) e os requerimentos para o crescimento dos cabritinhos são, proporcionalmente, menores do que os dos bezerros. Os recentes avanços revelaram, ainda, que os caprinos são menos sensíveis à intoxicação por cobre, toleram níveis de molibdênio até 10 vezes maiores e necessitam de mais iodo que os bovinos, pela maior transferência do iodo da dieta para o leite (Meschy 2000). No Brasil, ainda existem poucos estudos sobre exigências minerais de caprinos e os valores recomendados devem ser considerados como uma sugestão inicial e provisória para a formulação das die- 
tas para a espécie (Carvalho et al. 2003, Costa et al. 2003).

Com o objetivo de verificar alternativas na suplementação mineral, que diminuam as despesas e não impliquem em perda de produtividade, neste estudo avaliou-se o desempenho ponderal, os custos e os aspectos nutricionais e clínicos de caprinos jovens submetidos a dois tipos de suplementação mineral.

\section{MATERIAL E MÉTODOS \\ Instalações, animais e manejo}

O estudo foi realizado no Setor de Caprinocultura da UFRRJ e teve a duração de 148 dias (9.12.02 - 6.5.03). Foram utilizadas 16 fêmeas 3/4 Boer-Saanen, previamente vermifugadas (8.12.02 e 18.2.03) e mantidas em regime de confinamento em piso ripado. Oito animais eram recém-desmamados (com 3-4 meses) e oito tinham aproximadamente 13 meses. Na formação dos dois grupos experimentais, os animais foram separados por faixa etária e mantidos agrupados em baias diferentes. Dessa forma, para um mesmo esquema de suplementação mineral, formou-se um grupo com quatro animais pequenos e outro com quatro animais maiores.

Duas vezes por semana, os animais eram conduzidos a um piquete, próximo do aprisco, para tomarem sol e se exercitarem.

\section{Tratamentos}

Os capins andropogon (Andropogon gayanus) e elefante (Pennisetum purpureum), oriundos das capineiras ao redor do aprisco, foram utilizados como volumosos. Todos os animais recebiam sempre o mesmo capim e o esquema de corte das capineiras alternava a oferta de um ou de outro capim. 0 volumoso era diariamente cortado e picado antes de ser ofertado, duas vezes ao dia (às 8 e às 15 horas) para os animais. Após ser colocado nos cochos, o volumoso era uniformemente misturado com uma ração concentrada (formulada sem mistura mineral), contendo farelo de trigo $(550 \mathrm{~g} / \mathrm{kg})$, fubá ( $200 \mathrm{~g} / \mathrm{kg}$ ) e farelo de soja $(250 \mathrm{~g} / \mathrm{kg}$ ). A ração era oferecida na base de $300 \mathrm{~g} / \mathrm{cab}$./dia para os animais pequenos e 500 $\mathrm{g} / \mathrm{cab}$./dia para os maiores. A oferta de alimentos sempre proporcionou sobras de 5 a 10\%do material colocado nos cochos.

Quatro animais pequenos e quatro grandes receberam um suplemento mineral comercial que, segundo informações no rótulo, continha, por quilograma, $130 \mathrm{~g}$ de $\mathrm{Ca} ; 136,5 \mathrm{~g}$ de $\mathrm{Na}$; $65 \mathrm{~g}$ de $\mathrm{P} ; 12 \mathrm{~g}$ de S; $8 \mathrm{~g}$ de $\mathrm{Mg} ; 1500 \mathrm{mg}$ de Fe; $1200 \mathrm{mg}$ de $\mathrm{Cu} ; 2500 \mathrm{mg}$ de $\mathrm{Zn} ; 1000 \mathrm{mg}$ de $\mathrm{Mn} ; 100 \mathrm{mg}$ de I; $80 \mathrm{mg}$ de Co e $8 \mathrm{mg}$ de Se. De forma idêntica, quatro animais pequenos e quatro maiores receberam o suplemento seletivo formulado com cloreto de sódio (239 gNa/kg), superfosfato simples (34 $\mathrm{gP} / \mathrm{kg}$ ) e sulfato de cobre (1244 $\mathrm{mgCu} / \mathrm{kg})$. 0 sal seletivo foi proposto após o exame nutricional e clínico do rebanho. Embora exista informação segura (Tokarnia et al. 1971) de que a principal deficiência mineral nesta região é a de cobre, optou-se, em função dos quatro animais recém-desmamados, por incluir uma fonte de fósforo no sal seletivo.

Os suplementos minerais eram regularmente colocados em cochos de madeira ( $20 \times 20 \times 6 \mathrm{~cm})$; quando as sobras estavam em torno de $10 \%$ um novo reabastecimento das mistu- ras (100 g para os animais menores e de $200 \mathrm{~g}$ para os maiores) era feito e a data era anotada. Com esses dados, mensalmente, era realizada a determinação do consumo dos suplementos minerais.

Os animais eram pesados a cada 30 dias, sempre em jejum hídrico e sólido de, no mínimo, 12 horas.

\section{Coleta de dados}

Para se determinar o consumo de nutrientes, entre $10 \mathrm{e}$ 14.2.2003, foram feitas pesagens e amostragens do capim andropogon (ofertado entre 4 e 18.2.03), da ração concentrada e das sobras. A partir dessas amostras, determinaramse os teores de matéria seca (MS), proteína bruta (PB), fósforo (P), cálcio (Ca), sódio (Na), cobre (Cu), zinco $(\mathrm{Zn})$ e cobalto (Co). Esses nutrientes foram determinados, segundo os protocolos analíticos descritos na AOAC (1990), e seus valores encontram-se no Quadro 3.

No início (9.12.02) e no final (26.4.03) do experimento, amostras de sangue foram coletadas para quantificação de leucócitos, hemácias, hemoglobina, hematócrito e proteínas plasmáticas. Nestas datas também foram feitas fotografias da região periocular, pois, na formação dos lotes, observouse que vários animais possuíam despigmentação dos pêlos ao redor dos olhos, que poderia ser secundária à deficiência de cobre, uma vez que o rebanho não vinha recebendo qualquer tipo de suplementação mineral. Apenas para checar esta suspeita e comparar os efeitos dos dois suplementos na recuperação da acromotriquia periocular, aplicou-se, no início do estudo, 0,6 mL de glicinato de cobre (20 mgCu/mL) em um animal com a pelagem bastante "fosca" e acentuada acromotriquia periocular. Para evitar qualquer mudança em seu manejo, esse animal foi mantido sempre junto ao resto do rebanho, que não recebia nenhum tipo de suplementação mineral.

As variáveis analisadas foram o ganho de peso médio diário, o consumo e a despesa com os dois suplementos minerais, a ingestão de matéria seca, fósforo, cálcio, sódio, cobre, zinco e cobalto, o aspecto geral (fezes, apetite, alterações comportamentais) e alguns parâmetros sangüíneos. Apenas os dados de desenvolvimento ponderal foram submetidos à análise de variância e as médias foram comparadas por intermédio do teste de Tukey, assumindo-se 5\%de probabilidade de erro.

\section{RESULTADOS}

Não foram encontradas diferenças significativas no ganho de peso médio diário para os grupos que consumiram os dois tipos de suplemento mineral (Quadro 1). Entretanto, houve pequena variação entre os animais pequenos, que receberam 0 sal seletivo (ganharam, em média, $51,7 \mathrm{~g} /$ dia) e os que consumiram o sal mineral comercial (ganharam, em média, 57,8 g/dia). Já o ganho de peso diário dos animais maiores foi de $52,5 \mathrm{~g} / \mathrm{d}$ para os que receberam o sal seletivo e de $52 \mathrm{~g} / \mathrm{d}$ para os que tiveram acesso ao suplemento mineral comercial. (Quadro 1)

Em relação ao consumo de suplementos, o grupo de ani- 
Quadro 1. Desempenho ponderal de fêmeas caprinas frente a suplementação mineral comercial e seletiva

\begin{tabular}{|c|c|c|c|c|c|c|c|}
\hline \multicolumn{8}{|c|}{ Lote suplementado com sal mineral comercial } \\
\hline \multirow{2}{*}{$\begin{array}{l}\text { Tamanho e } \\
\text { número do } \\
\text { animal }\end{array}$} & \multicolumn{6}{|c|}{ Datas das pesagens e pesos individuais } & \multirow{2}{*}{$\begin{array}{c}\text { Ganho mé- } \\
\text { dio diário } \\
\text { (g/dia) }\end{array}$} \\
\hline & 9.dez & 9.jan & 9.fev & 9.mar & 9.abr & 6.mai & \\
\hline Pequeno 51 & 12,1 & 13,1 & 15,0 & 15,8 & 17,2 & 19,4 & 49,3 \\
\hline Pequeno 46 & 15,0 & 16,0 & 17,1 & 17,6 & 18,6 & 20 & \\
\hline Pequeno 47 & 15,9 & 17,8 & 20,2 & 21,0 & 23,2 & 25,5 & 64,9 \\
\hline Pequeno 42 & 16,5 & 19,0 & 22,3 & 23,5 & 25,4 & 28 & 80,4 \\
\hline Maior 34 & 33,8 & 37,2 & 38,6 & 38,0 & 39,8 & 42,0 & 55,4 \\
\hline Maior 35 & 32,0 & 34,2 & 35,5 & 35,9 & 37,5 & 40,5 & 57,4 \\
\hline Maior 38 & 27,0 & 29,0 & 30,6 & 30,2 & 31,9 & 32,2 & 35,1 \\
\hline Maior 30 & 28,0 & 30,1 & 32,8 & 32,9 & 35,4 & 36,9 & 60,1 \\
\hline \multirow[t]{2}{*}{ Média } & 22,54 & 24,55 & 26,51 & 26,86 & 28,63 & 30,66 & $54,9 \underline{a}$ \\
\hline & \multicolumn{6}{|c|}{ Lote suplementado com sal seletivo } & \\
\hline \multirow{2}{*}{$\begin{array}{l}\text { Tamanho e } \\
\text { número do } \\
\text { animal }\end{array}$} & \multicolumn{6}{|c|}{ Datas das pesagens e pesos individuais } & \multirow{2}{*}{$\begin{array}{l}\text { Ganho mé- } \\
\text { dio diário } \\
\text { (g/dia) }\end{array}$} \\
\hline & 9.dez & 9.jan & 9.fev & 9.mar & 9.abr & 6.mai & \\
\hline Pequeno 53 & 13,9 & 15,8 & 16,4 & 17,0 & 17,8 & 20,0 & 41,2 \\
\hline Pequeno 45 & 14,5 & 17,5 & 18,3 & 19,9 & 21,4 & 23, & 60,8 \\
\hline Pequeno 40 & 14,1 & 14,8 & 16,3 & 16,9 & 17,6 & 19,5 & 36,5 \\
\hline Pequeno 41 & 17,2 & 19,8 & 22,7 & 23,9 & 24,6 & 27,3 & 68,2 \\
\hline Maior 37 & 26,5 & 28,5 & 29,2 & 29,9 & 31,6 & 34,0 & 50,7 \\
\hline Maior 36 & 30,8 & 32,5 & 33,8 & 36,0 & 37,4 & 39,0 & 55,4 \\
\hline Maior 33 & 34,2 & 36,3 & 37,5 & 37,9 & 39,6 & 41,8 & 51,4 \\
\hline Maior 32 & 34,0 & 35,2 & 36,6 & 37,3 & 39,8 & 41,8 & 52,7 \\
\hline Média & 23,15 & 25,05 & 26,35 & 27,35 & 28,73 & 30,86 & 52,1 a \\
\hline
\end{tabular}

$\bar{a}$ Médias em mesma coluna, seguidas de letras iguais, não diferem entre $s i$ pelo teste $\mathrm{T}$.
Quadro 2. Consumo e despesas com a suplementação mineral comercial e seletiva

\begin{tabular}{|c|c|c|c|c|}
\hline \multirow[t]{2}{*}{ Consumo } & \multicolumn{2}{|c|}{ Animais maiores } & \multicolumn{2}{|c|}{ Animais pequenos } \\
\hline & $\begin{array}{l}\text { Sal seletivo } \\
\quad(n=4)\end{array}$ & $\begin{array}{l}\mathrm{SMC}^{\mathrm{a}} \\
(\mathrm{n}=4)\end{array}$ & $\begin{array}{l}\text { Sal seletivo } \\
\quad(n=4)\end{array}$ & $\begin{array}{l}\mathrm{SMCa}^{\mathrm{a}} \\
(\mathrm{n}=4)\end{array}$ \\
\hline 1 até 30 dias & 2700 & 3200 & 600 & 600 \\
\hline 31 até 60 dias & 1900 & 3900 & 700 & 500 \\
\hline 61 até 90 dias & 1200 & 1400 & 500 & 400 \\
\hline 90 até 120 dias & 1000 & 1800 & 300 & 400 \\
\hline 121 até 148 dias & 400 & 600 & 400 & 300 \\
\hline Soma (g) & 7200 & 10900 & 2500 & 2200 \\
\hline Média/dia & 12,2 & 18,4 & 4,2 & 3,7 \\
\hline $\mathrm{R} \$ / \mathrm{kg}$ & 0,44 & 1,14 & 0,44 & 1,14 \\
\hline $\begin{array}{c}\text { Despesa } \\
\text { (R\$/148 dias) }\end{array}$ & 3,17 & 12,42 & 1.10 & 2,51 \\
\hline
\end{tabular}

aSal mineral comercial.

ral; apenas ingerindo o volumoso, cuja amostra analisada continha $3 \mathrm{mgCu} / \mathrm{kgMS}$ (Quadro 3), concentração sabidamente capaz de resultar em moderada deficiência de cobre. Esse teor de cobre no volumoso multiplicado pela ingestão diária desse alimento (Quadro 4), resulta na ingestão diária de cobre advinda da forragem, cujos valores para todos os grupos se situaram entre 16 e 20\%das necessidades diárias (Quadro 5).

Os exames de sangue dos animais submetidos aos dois esquemas de suplementação mineral podem ser observados no Quadro 7. Esses exames revelaram que houve aumento do número de hemácias, da concentração de hemoglobina e

Quadro 3. Composição químico-bromatológica dos alimentos

\begin{tabular}{lcccccccc}
\hline Alimento & $\mathrm{MS}$ & $\mathrm{PB}$ & $\mathrm{P}$ & $\mathrm{CA}$ & $\mathrm{Na}$ & $\mathrm{Cu}$ & $\mathrm{Zn}$ & $\mathrm{Co}$ \\
\cline { 2 - 7 } & (\%) & (\%MS) & (\%MS) & (\%MS) & (\%MS) & (mg/kgMS) & (mg/kgMS) & (mg/kgMS) \\
\hline Ração concentrada & 89,6 & 20,8 & 0,68 & 0,27 & 0,03 & 8 & 71 & 0,14 \\
Capim Andropogon & 35,4 & 5,96 & 0,23 & 0,48 & 0,02 & 3 & 38 & 0,18
\end{tabular}

mais maiores, que recebeu o sal seletivo, consumiu menos $3,7 \mathrm{~kg}$ de suplemento mineral. Como o custo da suplementação mineral é o produto do consumo médio diário pelo preço do quilograma do suplemento, houve uma drástica redução no custo da suplementação com o sal seletivo, uma vez que este é mais barato e menos ingerido. A despesa com o suplemento mineral comercial foi 3,9 (para o lote maior) e 2,3 (para o lote pequeno) vezes maior do que aquela verificada com o sal seletivo. (Quadro 2)

Observou-se, ainda, que todos os animais de ambos os grupos apresentaram evidente melhora da qualidade da pelagem geral e aumento da pigmentação na pelagem periocular (Fig. 1 a 6). Esses últimos dados indicam que os animais, antes do experimento, passavam por certo grau de deficiência de cobre que foi corrigida, em ambos os tratamentos, pela ingestão desse elemento contido nos suplementos minerais. Essa hipótese também foi confirmada pela correção da acromotriquia periocular verificada no animal que recebeu cobre injetável (Fig. 5 e 6, Caprino 17) e que permaneceu junto ao resto do rebanho, sem ser suplementado com qualquer mistura mine- do hematócrito nos animais maiores que foram suplementados com ambos os suplementos minerais. Esses fatos, associados ao histórico (área deficiente em cobre e rebanho

Quadro 4. Consumo de matéria seca da ração (CMSr) e de matéria seca do volumoso (CMSv) e de matéria seca total (CMSt)

\begin{tabular}{cccccccc}
\hline $\begin{array}{c}\text { Grupo expe- } \\
\text { rimental }\end{array}$ & $\mathrm{CMSr}^{\mathrm{a}}$ & $\mathrm{CMSV}^{\mathrm{a}}$ & $\mathrm{CMSt}^{\mathrm{a}}$ & $\begin{array}{c}\text { Peso } \\
\text { Vivo }\end{array}$ & $\mathrm{CMSr}^{\mathrm{c}}$ & $\mathrm{CMSv}^{\mathrm{c}}$ & $\mathrm{CMSt}^{\mathrm{c}}$ \\
\hline $\begin{array}{c}\text { Animais mai- } \\
\text { ores (SMCd) }\end{array}$ & 0,448 & 0,806 & 1,254 & 34,40 & 1,30 & 2,34 & 3,64 \\
$\begin{array}{c}\text { Animais mai- } \\
\text { ores (SS) }\end{array}$ & 0,448 & 0,721 & 1,169 & 34,30 & 1,31 & 2,10 & 3,41 \\
$\begin{array}{c}\text { Animais peque- } \\
\text { nos (SMC) }\end{array}$ & 0,269 & 0,361 & 0,630 & 18,65 & 1,44 & 1,93 & 3,37 \\
$\begin{array}{c}\text { Animais peque- } \\
\text { nos (SS) }\end{array}$ & 0,269 & 0,319 & 0,588 & 18,43 & 1,46 & 1,73 & 3,19 \\
& & & & & & &
\end{tabular}

aEm kg/cab./dia.

${ }^{b} \mathrm{Em} \mathrm{kg}$, correspondendo à media obtida em 9.2.2003 (Quadro 1).

C Em \%do peso vivo.

d Sal mineral comercial.

e Sal seletivo. 

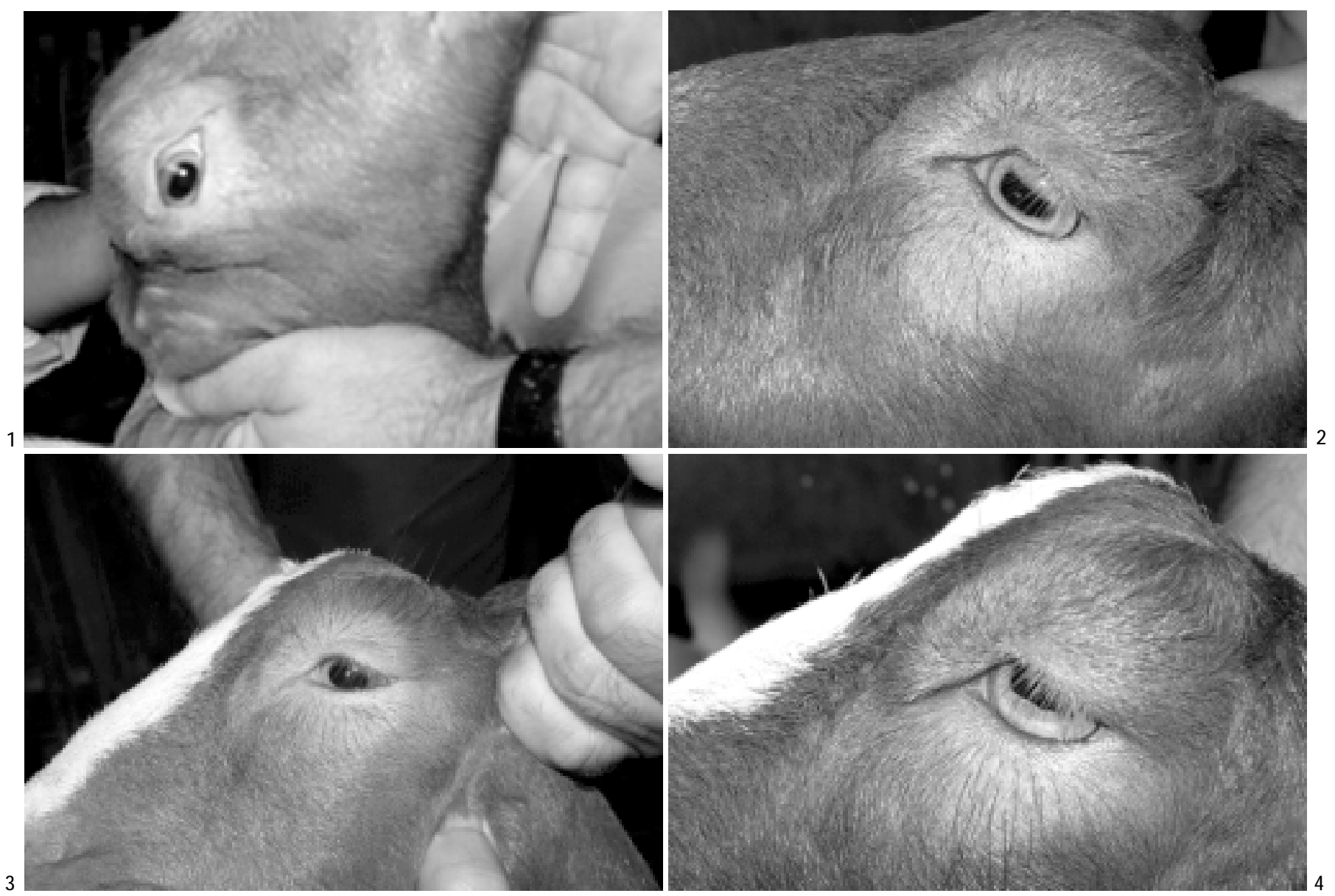

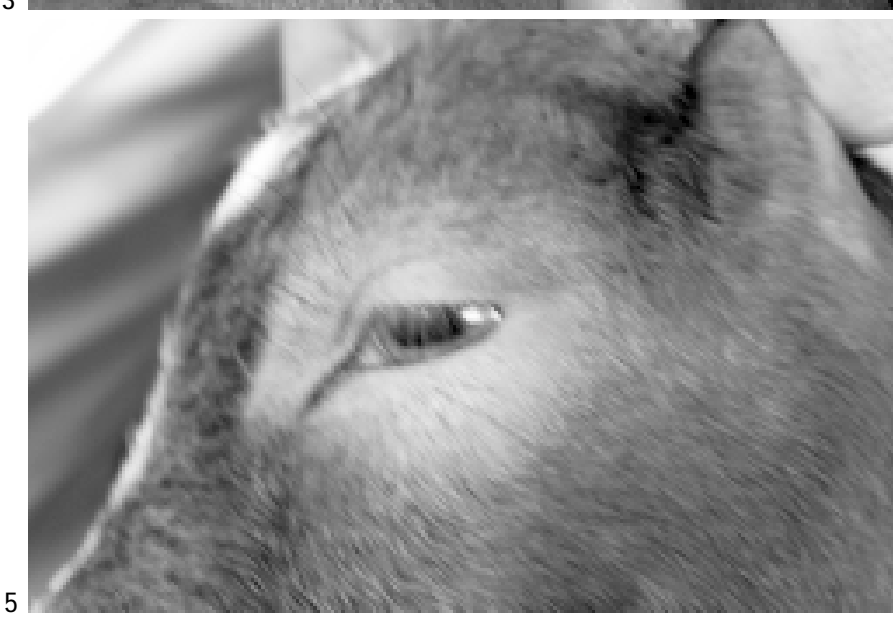

Fig. 1. Modificação na pigmentação periocular do Caprino 46 que recebeu o sal mineral comercial no início do experimento (9.12.02).

Fig. 3. Modificação na pigmentação periocular do Caprino 53 que recebeu o sal seletivo, no início do experimento (9.12.02).

Fig. 5. Modificação na pigmentação periocular do Caprino 17 que recebeu o cobre injetável, no início do experimento (9.12.02).
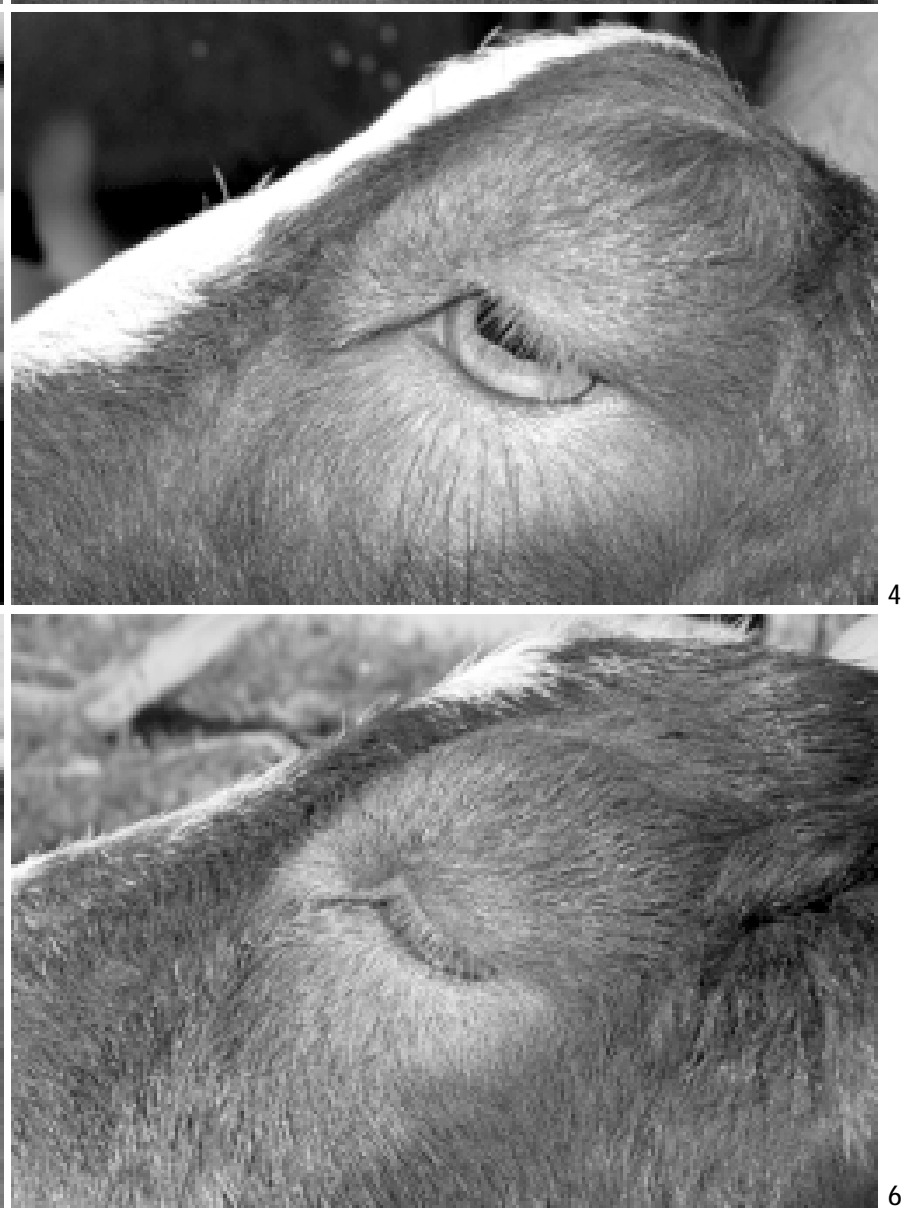

Fig. 2. Modificação na pigmentação periocular do Caprino 46 que recebeu o sal mineral comercial ao final do experimento (26.4.03).

Fig. 4. Modificação na pigmentação periocular do Caprino 53 que recebeu o sal seletivo ao final do experimento (26.4.03).

Fig. 6. Modificação na pigmentação periocular do Caprino 17 que recebeu o cobre injetável ao final do experimento (26.4.03). 
Quadro 5. Consumo de fósforo (P), cálcio (Ca), sódio (Na), cobre (Cu), zinco (Zn)e de cobalto (Co)

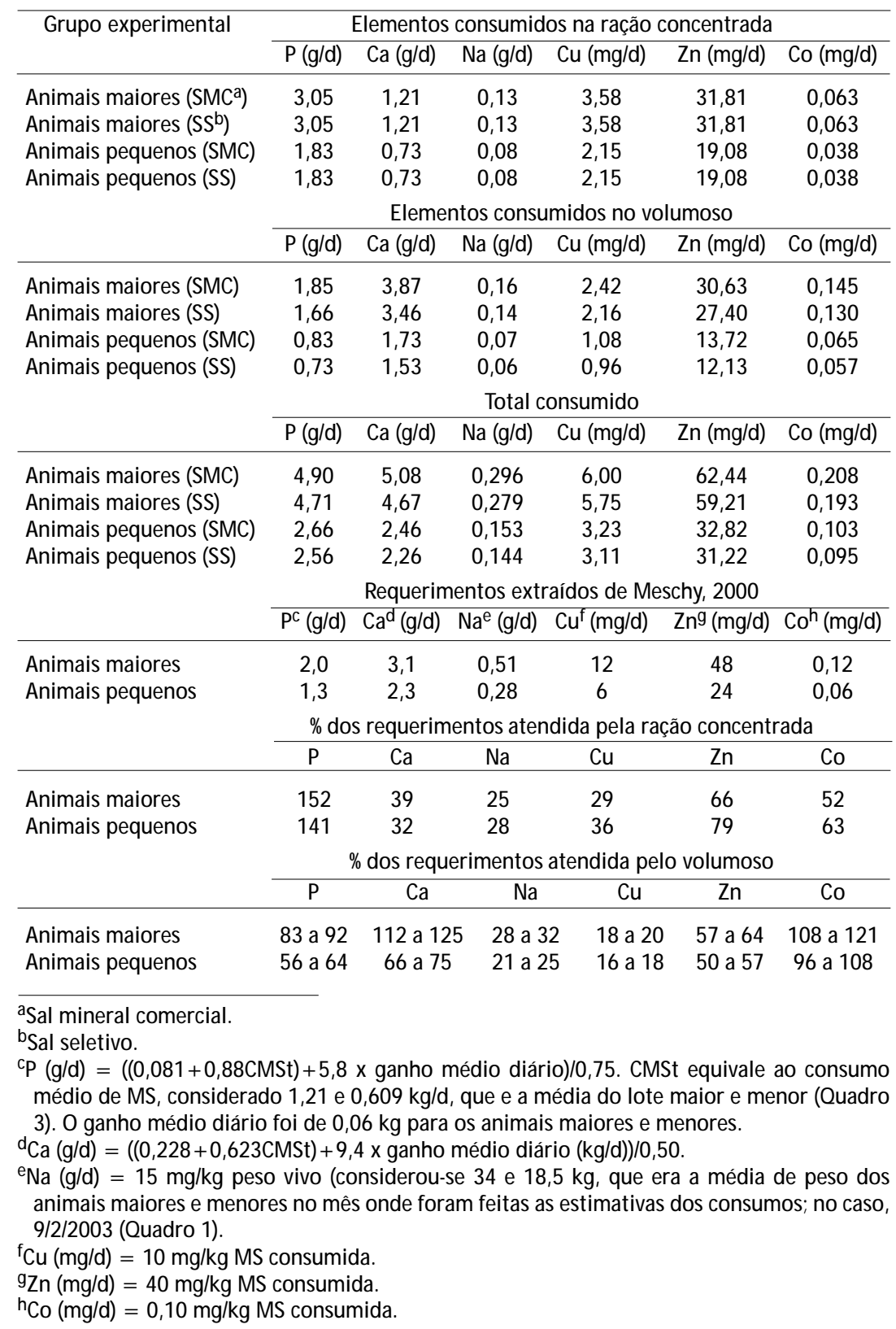

não "mineralizado"), ao pequeno consumo diário de cobre advindo do volumoso, e à evidente melhora da acromotriquia periocular, reforçam a hipótese de que os animais eram moderadamante deficientes em cobre e saíram deste quadro ao receberem ambos os suplementos minerais.

\section{DISCUSSÃO}

Como a única diferença entre os dois grupos experimentais foi a disponibilidade de diferentes misturas minerais, sendo que uma delas continha apenas $\mathrm{Na}, \mathrm{Pe} \mathrm{Cu}$, os ganhos médios diários similares só podem ser explicados pelo fato de a ração concentrada e de o volumoso já conterem as quantida- des suficientes dos demais minerais necessários ao metabolismo dos animais. Para checar essa hipótese, ao discriminarmos os consumos diários dos minerais (Quadros 5 e 6), verificamos que (1) os requerimentos de $P$, nos dois grupos de animais, foram supridos somente com o consumo da ração concentrada; (2) os requerimentos de $\mathrm{Ca}$, e de $\mathrm{Co}$ dos animais maiores, foram totalmente atendidos pelo consumo do volumoso; (3) a ingestão da ração concentrada e do volumoso foi capaz de suprir as necessidades de Zn; e (4) apenas as exigências de $\mathrm{Na}$ e de $\mathrm{Cu}$ não foram atendidas pelo consumo da ração concentrada e do volumoso e, conseqüentemente, com a ingestão dos dois suplementos minerais, essas demandas 
Quadro 6. Consumo médio diário de sódio (Na-rv) e cobre (Cu-rv) na ração e no volumoso, requerimento diário de sódio e de cobre, consumo médio diário dos suplementos (C-S), teor de sódio (Na-S) e de cobre nos suplementos (Cu-S), consumo médio diário de sódio (Na-IS) e de cobre (Cu-IS) oriundo da ingestão dos suplementos

\begin{tabular}{|c|c|c|c|c|c|c|}
\hline $\begin{array}{l}\text { Grupo experi- } \\
\text { mental }\end{array}$ & $\begin{array}{c}N a-r v^{a} \\
(g / d)\end{array}$ & $\begin{array}{l}\text { Requeri- } \\
\text { mento de } \\
\mathrm{Na}(\mathrm{g} / \mathrm{d})^{\mathrm{a}}\end{array}$ & $\begin{array}{l}\text { Diferença } \\
(\mathrm{g} / \mathrm{d})\end{array}$ & $\begin{array}{l}C-S^{b} \\
(g / d)\end{array}$ & $\begin{array}{l}\mathrm{Na}-\mathrm{S} \\
\mathrm{g} / \mathrm{kg}\end{array}$ & $\begin{array}{l}\mathrm{Na}-\mathrm{IS} \\
(\mathrm{g} / \mathrm{d})\end{array}$ \\
\hline $\begin{array}{l}\text { Animais mai- } \\
\text { ores (SMCC) }\end{array}$ & 0,296 & 0,51 & $-0,214$ & 18,4 & 136,5 & 2,51 \\
\hline $\begin{array}{l}\text { Animais mai- } \\
\text { ores }\left(\mathrm{SS}^{\mathrm{d}}\right)\end{array}$ & 0,279 & 0,51 & $-0,231$ & 12,4 & 239 & 2,96 \\
\hline $\begin{array}{l}\text { Animais peque- } \\
\text { nos (SMC) }\end{array}$ & 0,153 & 0,28 & $-0,127$ & 3,7 & 136,5 & 0,51 \\
\hline \multirow[t]{2}{*}{$\begin{array}{l}\text { Animais peque- } \\
\text { nos (SS) }\end{array}$} & 0,144 & 0,28 & $-0,136$ & 4,2 & 239 & 1,00 \\
\hline & $\begin{array}{l}\text { Cu-rva } \\
\text { (mg/d) }\end{array}$ & $\begin{array}{l}\text { Requeri- } \\
\text { mento de } \\
\mathrm{Cu}(\mathrm{mg} / \mathrm{d})^{\mathrm{a}}\end{array}$ & $\begin{array}{l}\text { Diferença } \\
\mathrm{mg} / \mathrm{d})\end{array}$ & $\begin{array}{l}C-S^{b} \\
(g / d)\end{array}$ & $\begin{array}{l}\mathrm{Cu}-\mathrm{S} \\
\mathrm{mg} / \mathrm{kg}\end{array}$ & $\begin{array}{r}\text { Cu-IS } \\
\text { (mg/d) }\end{array}$ \\
\hline $\begin{array}{l}\text { Animais mai- } \\
\text { ores (SMC) }\end{array}$ & 6,00 & 12 & $-6,00$ & 18,4 & 1200 & 22,08 \\
\hline $\begin{array}{l}\text { Animais mai- } \\
\text { ores (SS) }\end{array}$ & 5,75 & 12 & $-6,25$ & 12,4 & 1244 & 15,43 \\
\hline $\begin{array}{l}\text { Animais peque- } \\
\text { nos (SMC) }\end{array}$ & 3,23 & 6 & $-2,77$ & 3,7 & 1200 & 4,44 \\
\hline $\begin{array}{l}\text { Animais peque- } \\
\text { nos (SS) }\end{array}$ & 3,11 & 6 & $-2,89$ & 4,2 & 1244 & 5,22 \\
\hline
\end{tabular}

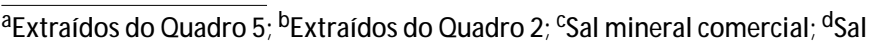
seletivo. foram supridas (Quadro 6). Além dos cálculos sobre o consumo de fósforo, cálcio, cobalto e zinco demonstrarem numericamente que as exigências desses minerais foram totalmente atendidas apenas com a ingestão da ração concentrada e do volumoso, clinicamente os animais não apresentaram quaisquer sinais diretos ou indiretos de deficiência desses elementos.

Dessa forma, para esta específica situação, apenas a suplementação com $\mathrm{NaCl}$ associado ao sulfato de cobre seria adequada para atender as necessidades minerais dos animais, sem causar prejuízos a sua saúde e produtividade. Reforçando esta recomendação, há o trabalho de Tokarnia et al. (1971), que descreve apenas a deficiência de cobre acometendo bovinos e ovinos nesta região do Estado do Rio de Janeiro. A decisão de incluir uma fonte de fósforo no sal seletivo foi tomada, uma vez que os quatro animais menores, que receberiam o sal seletivo eram recém-desmamados e estavam em fase de intenso crescimento ósseo. Um aspecto importante a ser ressaltado é que os animais que ingeriram o superfosfato simples como fonte de fósforo, mantiveram-se saudáveis por todo o experimento.

0 maior consumo de sal mineral comercial verificado no grupo de animais maiores, ao que tudo indica, deveu-se aos baixos teores de cloreto de sódio (136,5 g de Na/kg, 0 que equivale a aprox. $341 \mathrm{~g}$ de $\mathrm{NaCl} / \mathrm{kg}$ ou $34 \%$, enquanto

Quadro 7. Exames de sangue dos animais que receberam os suplementos minerais comercial e seletivo

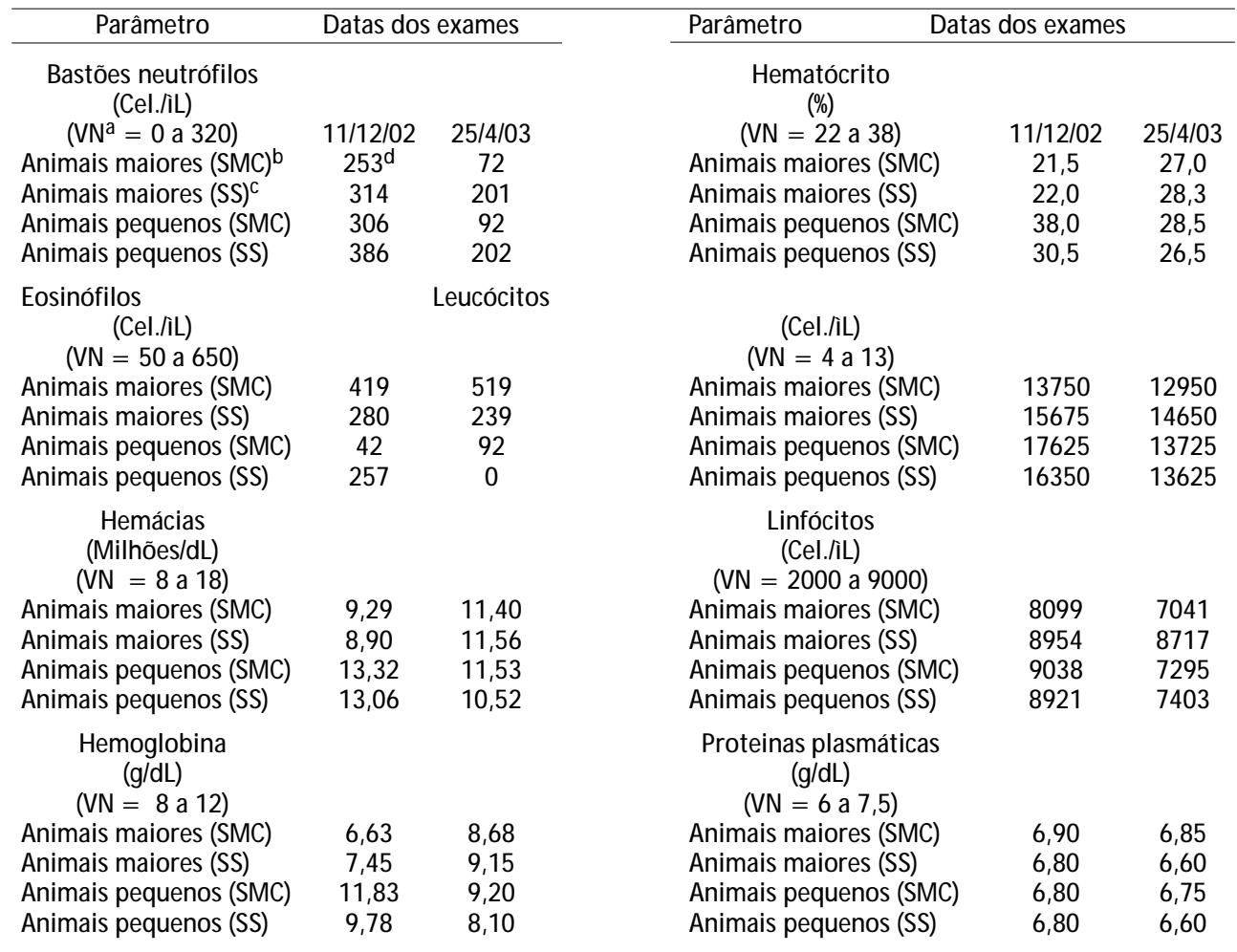

avalores normais para a espécie caprina (Jain 1993, p. 22).

bSal mineral comercial.

'Sal seletivo.

dCada valor corresponde à média de quatro animais. 
que o sal seletivo possuía $239 \mathrm{~g} \mathrm{Na} / \mathrm{kg}<=>597,5 \mathrm{~g} \mathrm{NaCl} / \mathrm{kg}$ ou $59,75 \%$ Sabe-se que o $\mathrm{NaCl}$ é 0 fator que controla a ingestão voluntária de um suplemento mineral, portanto, uma concentração menor deste em uma mistura, propiciará um maior consumo e vice-versa.

0 menor consumo de sal seletivo verificado no grupo de animais menores deveu-se, provavelmente, ao exagerado consumo nos primeiros meses do estudo (Quadro 2). Como os animais não eram suplementados (eram lactentes), possivelmente tinham uma grande preferência pelo sal seletivo, que continha mais $\mathrm{NaCl}$ do que o sal comercial. Nos últimos 2 meses, o consumo foi praticamente idêntico nos dois grupos de animais menores (Quadro 2).

0 ensaio de reversão alicerçado em um protocolo experimental, onde um grupo de animais recebe uma mistura mineral comercial e outro, uma mistura mineral denominada de sal seletivo (que sempre conterá menos elementos minerais), é uma medida prudente, pois pode ser arriscado abandonar de imediato um programa de suplementação mineral comercial já existente. Dessa forma, o ensaio de reversão nada mais é do que a tentativa de estabelecer a(s) quantidade(s) ideal(is) do(s) mineral(is) a ser(em) suplementada(s) que resulte $(\mathrm{m})$ no melhor desempenho dos animais associado ao menor custo. Obviamente, os resultados desse ensaio devem ser somente aplicados ao rebanho onde ele foi realizado.

A suplementação mineral seletiva, conceito que significa fornecer apenas o(s) elemento(s) mineral(is) que efetivamente está(ão) em falta na dieta dos animais, deve ser sempre proposto com base no manejo nutricional dos animais e no exame clínico-epidemiológico dos rebanhos (Peixoto et al. 2003).

\section{CONCLUSÕES}

Os resultados obtidos, neste estudo, permitem concluir que caprinos criados com volumosos tropicais e suplementados com modestas quantidades de ração concentrada, podem ser mantidos em perfeito estado de saúde, recebendo um suplemento mineral que contenha apenas os elementos sabidamente deficitários em sua dieta. No caso específico deste rebanho, o sal seletivo, de custo bem menor, deverá conter apenas sulfato de cobre associado ao cloreto de sódio.

Agradecimentos.- Os autores manifestam agradecimentos ao responsável pelo Setor de Caprinocultura da UFRRJ, Sr. Everton da Silva Mattos, pelo apoio logístico dado durante a condução deste estudo; ao Dr. Rogério Magnoli Costa (www.exitorural.com.br) e ao Sr. Darley Ângelo Mantovani, pela realização das analises de minerais nos alimentos estudados.

\section{REFERÊNCIAS}

AFRC - Agricultural and Food Research Council 1993. Energy and Protein Requirements of Ruminants. CAB International, Cambridge University Press, Cambridge. $159 \mathrm{p}$.

AOAC - Association of Official Analytical Chemists 1990. 15th ed. Official Methods of Analysis. Vol.1. 15th ed. Arlington, VA. 1117p.

Carvalho F.F.R., Resende K.T., Vitti D.M.S.S., Ferreira A.C.D. \& Abdalla A.L. 2003. Perda endógena e exigência de fósforo para a mantença de cabritos Saanen. Revta Bras. Zootec. 32(2):411-417.

Costa R.G., Resende K.T., Rodrigues M.T., Espechit C.B. \& Queiroz A.C. 2003. Exigências de minerais para cabras durante a gestação: $\mathrm{Na}, \mathrm{K}, \mathrm{Mg}, \mathrm{S}$, Fe e Zn. Revta Bras. Zootec. 32(2):431-436.

INRA 1989. Ruminant Nutrition, Recommended Allowances and Feed Tables. Institut National de la Recherche Agronomique, Paris. 121p.

Jain N.C. 1993. Schalm's Veterinary Hematology. Lea \& Febiger, Philadelphia, PA. $1221 p$.

Meschy F. 2000. Recent progress in the assessment of mineral requeriments of goats. Livest. Prod. Sci. 64(1):9-14.

NRC - National Research Council 1981. Nutrient Requirements of Domestic Animals: Nutrient Requeriments of Dairy Goats. National Academy Press, Washington, DC. 91 p.

Peixoto P.V., Malafaia P., Miranda L.V., Canella C.F.C., Canella Filho C.F.C. \& Vilas Boas F.V. 2003. Eficiência reprodutiva de matrizes bovinas de corte submetidas a três diferentes tipos de suplementação mineral. Pesq. Vet. Bras. 23(3):125-130.

Tokarnia C.H., Guimarães J.A., Canella C.F.C. \& Döbereiner J. 1971. Deficiências de cobre e cobalto em bovinos e ovinos em algumas regiões do Brasil. Pesq. Agropec. Bras. 6:61-77.

Tokarnia C.H., Döbereiner J., Peixoto P.V. \& Canella C.F.C. 2000. Deficiências minerais em animais de fazenda, principalmente bovinos. Pesq. Vet. Bras. 20 (3):127-138.

Zicarelli L. 2003. Alimentação da búfala leiteira. 1ํ Encontro de Bubalinocultores, 10-13 jul., Brasília, DF, p.1-29. 